\title{
Contact stiffness estimation for PMMA/STEEL contact pair
}

\author{
Davide Tonazzi ${ }^{1}$, Francesco Massi ${ }^{1}$, Yves Berthier ${ }^{2}$ \\ ${ }^{1}$ Sapienza University of Rome, DIMA, Italy, davide.tonazzi@uniroma1.it and francesco.massi@uniroma1.it \\ ${ }^{2}$ Institut National des Sciences Appliquée de Lyon, LaMCoS, France, yves.berthier@insa-lyon.fr
}

\begin{abstract}
Modelling of frictional contact systems with high accuracy needs the knowledge of several contact parameters that are mainly related to the properties of the contact interfaces. While the interface parameters cannot be directly obtained by performing local measurements, the values estimated by means of analytical/numerical models are not reliable to describe the contact behavior, which affects in a prominent way the complex contact phenomena. This work presents a newer approach for identifying reliable values of the normal contact stiffness between rough surfaces in both sliding and sticking conditions as a function of contact pressure, surface roughness and materials. The combination of dynamic experimental tests, on a dedicated set-up, with finite element modelling allowed for an indirect determination of the normal stiffness at the contact.
\end{abstract} body.

Keywords-- contact stiffness, dynamic test, roughness, third

\section{INTRODUCTION}

The correct modelling of contact interfaces is a key factor in many engineering applications that inherently include contacts between components: e.g. joints, tire road friction [1, 2], robotic contacts, rolling bearings [2-4], brake systems [5, 6], etc. The contact mechanics between component surfaces plays also a key role for understanding many tribological processes such as friction [7, 8], contact induced vibrations [7, 9-11], adhesion and wear [12-15]. Accurate contact modelling of such systems requires knowledge of interface contact parameters [16-18], such as contact stiffness [19-22], which are not easily available and completely understood.

The first works dealing with contact stiffness dealt with analytical approach of simple elastic model using Hertzian spherical contact. In the GW model [23] the contact interface is considered nominally flat with single scale roughness where the contact stiffness is obtained by statistical model.

A completely different method to measure contact stiffness is based on ultrasonic methods where high frequency waves are used to derive the stiffness from the interface [24]. Another method to measure contact stiffness and damping at the nanoscales has been presented by Asif et al [25]. A few works [26, 27] in literature are based on combined experimental and analytical/numerical approach for indirect measurement of the contact stiffness [28-30].

In this context the objective of the present work is the estimation of surface contact stiffness using a newer methodology that combines experiments and finite element approach for an indirect measure of its value in static and sliding condition.

Digital Object Identifier (DOI):

http://dx.doi.org/10.18687/LACCEI2019.1.1.503

ISBN: 978-0-9993443-6-1 ISSN: 2414-6390
On one hand, an experimental setup has been developed for measuring the contact stiffness both in sticking and sliding conditions, for different surface topographies, materials and average contact pressures. The frequency analysis of the system response allowed for identifying its dynamics, which is related to both the dynamics of the considered system and the interface contribution. On the other hand, a finite element model of the experimental setup has been developed, taking into account the dynamics of the system and the contact interface contribution. Comparison between numerical and experimental results allows for estimating the value of the normal contact stiffness.

\section{METHOD AND MATERIALS}

The proposed methodology for the estimation of the normal contact stiffness between two materials in contact is based on a dynamic method, developed through a combined numerical and experimental approach (Figure 1). By an experimental point of view, a newer setup has been designed and then used to perform dynamic tests, controlling and identifying its dynamic response. Afterwards, a 3D finite element model, updated and to be representative of the experimental setup, has been utilized to compare the numerical and experimental results for estimating the normal contact stiffness between the considered contact materials.

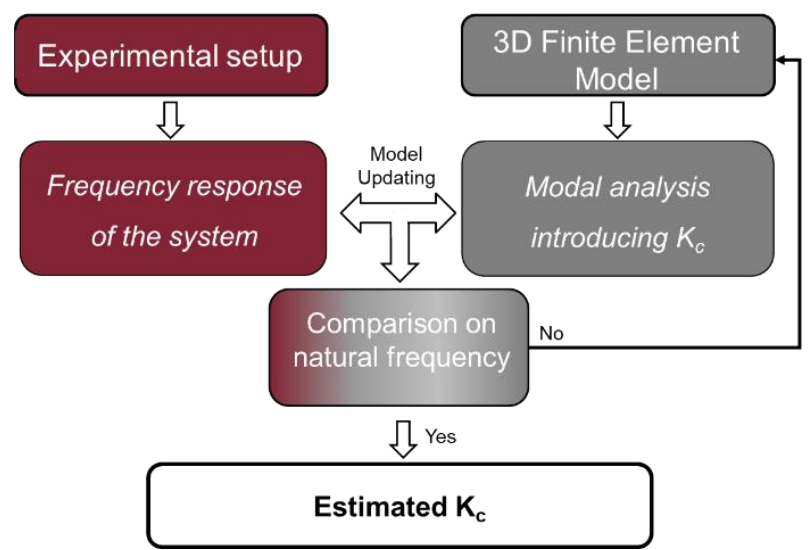

Figure 1.Overview of the proposed approach for the estimation of the contact stiffness.

Through the comparison between the results from the numerical model and the system frequency response from experiments, the value of the normal contact stiffness can be estimated by fitting the numerical eigenfrequencies of the investigated system with the results of the frequency analysis performed on the experimental setup.

$17^{\text {th }}$ LACCEI International Multi-Conference for Engineering, Education, and Technology: "Industry, Innovation, And Infrastructure for Sustainable Cities and Communities”, 24-26 July 2019, Jamaica. 
The experimental tribometer, designed to perform the experiments for the contact stiffness estimation, is presented in Figure 2.
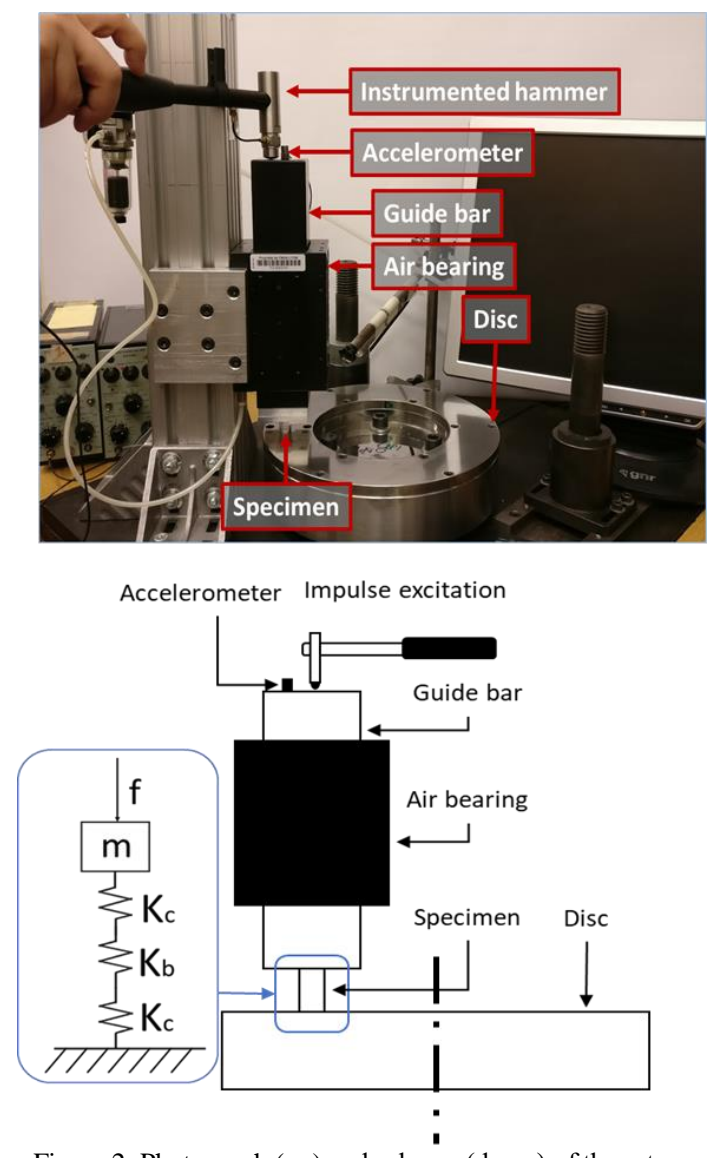

Figure 2. Photograph (up) and scheme (down) of the setup.

The setup has been designed to perform tests as a function of different materials (samples) in contact, different length of the samples and a wide range of the average contact pressure up to $1 \mathrm{MPa}$. The system is mainly characterized by a sample in contact with a massive steel disc and loaded by the weight of a vertical support (guide bar). In order to minimize the friction between the massive support and the frame, along the normal direction to the contact surface, an air guide based on air bearings technology is used. In such a way, the vertical support is free to vibrate in the normal direction. The experimental setup is equipped with a DC motor and a digital motion controller in order to perform measurements in both static and sliding condition with a well-controlled rotational speed.

After the characterization of the geometry and mechanical properties of the PMMA material, the samples have been obtained machined in three different lengths. After the cutting process, a face milling is used with a right combination of cutting head (diameter and cutters shape), rotational and feeding speed, allowing for obtaining a surface with desired surface parameters in terms of Ra and topography as shown in
Figure 3. After the milling process, the specimens have been cleaned in an ultrasound cleaning machine and then left to dry.

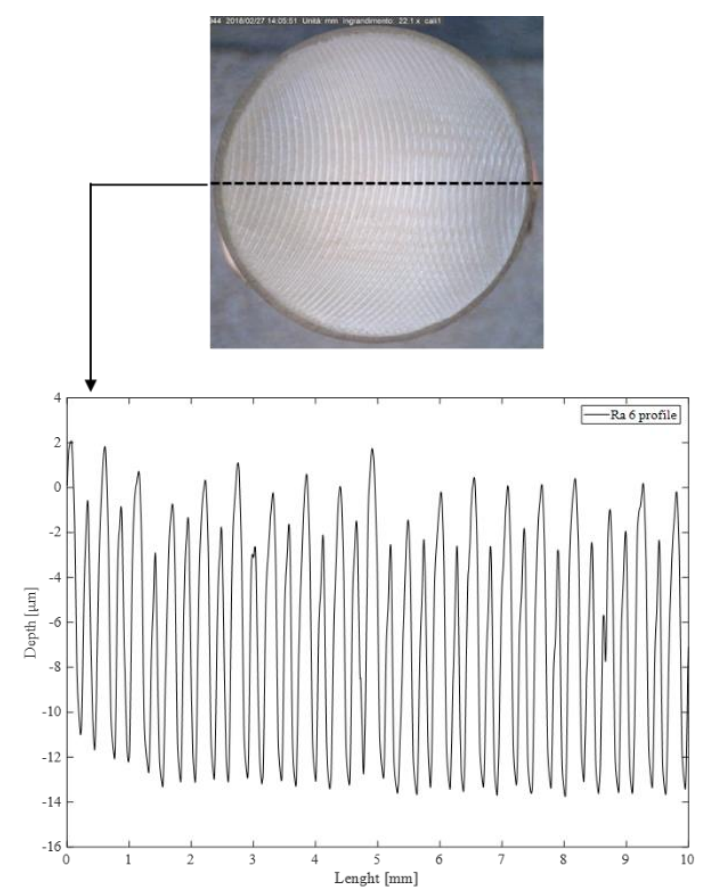

Figure 3. Microscope image (up) and 1D-roughness profile (down) for $\mathrm{Ra}=6 \mu \mathrm{m}$.

At this point, each single sample has been visually inspected and tested with a profilometer. The specimens which surfaces have met the roughness and planarity requirements have been used for the contact stiffness tests.

\begin{tabular}{c|c|c|c}
\hline \hline $\begin{array}{c}\text { Specimen's } \\
\text { requirement }\end{array}$ & $\begin{array}{c}\mathrm{Ra} \\
{[\boldsymbol{\mu m}]}\end{array}$ & $\begin{array}{c}\text { Slope tolerance } \\
{[\% \mathrm{o}]}\end{array}$ & $\begin{array}{l}\text { Flatness } \\
\text { tolerance [\%o] }\end{array}$ \\
\hline PMMA & $\begin{array}{c}\mathrm{Ra} \\
\text { target } \\
\pm 0,2\end{array}$ & 1 & 1 \\
\hline
\end{tabular}

Table 1. Requirements for the specimen used in the experiments.

A first measurement is carried out by placing the specimen in contact between the disc surface and the guide bar; successively, a dead mass is added on the top of the guide bar to obtain a desired average pressure at the contact interface between the sample and the disc. The dynamic response of the system to an impulsive excitation (hammer impact) is recorded, by an accelerometer placed at the top of the guide bar. The signal of the impulsive force and the system response have been recorded by a signal acquisition system with a sampling frequency of $10 \mathrm{kHz}$.

On the other hand, a finite element model (Figure 4) of the experimental setup has been developed using the ANSYS software; in order to reduce the model size and the complexity of the system, the numerical model includes only the disc 
assembly, the air bearing support with its guide bar and the sample as well. The presence of the shaft and bearings, the belt and the drive motor, and the related global dynamic contributions, have been taken into account adding an elastic support per unit area $\left(\mathrm{k}_{\text {support }}=100 \mathrm{~N} / \mathrm{m}^{3}\right)$ on the base of the disc assembly with the stiffness value calculated by updating the model with preliminary dynamic tests.

A hexahedral-dominant mesh has been used in the numerical model. Each 3D solid element has 16 nodes, for a total of 48 degrees of freedom. The model is composed of four main bodies: the disc, the guide bar, the air bearing and the specimen. For each body, a linear elastic material law has been taken into account with the following parameters:

- $\quad$ Steel Disc: Young Modulus E=201 GPa, Poisson coefficient $\nu=0.3$ and mass density $\rho=7930 \mathrm{~kg} / \mathrm{m}^{3}$;

- $\quad$ Linear air bearing (support and guide bar): Young Modulus E $=70 \mathrm{GPa}$, Poisson coefficient $v=0.3$ and mass density $\rho=2700 \mathrm{~kg} / \mathrm{m}^{3}$;

- PMMA specimen: Young Modulus E=4.5 GPa, Poisson coefficient $\nu=0.4$ and mass density $\rho=1190$ $\mathrm{kg} / \mathrm{m}^{3}$;

A finer mesh has been used for the specimen meshing, while a coarser mesh turned out to be sufficient for an accurate description of the other bodies in the frequency range of interest, for a total of 13884 elements in the model.

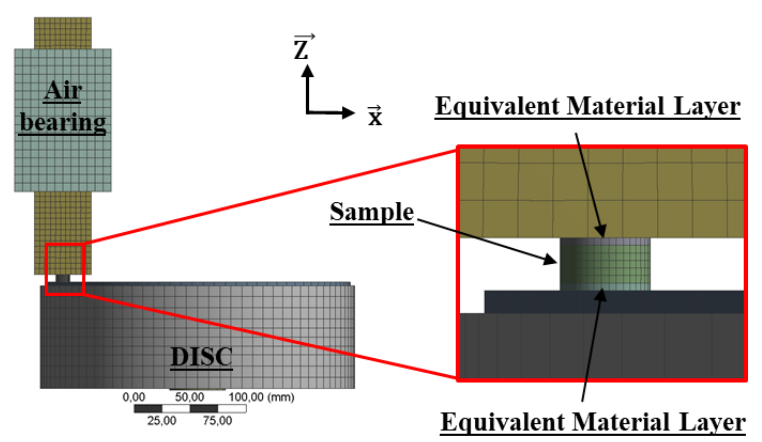

Figure 4. 3D finite element model of the developed experimental setup and zoom related to the sample in contact.

The updating with the experimental tests of each components and of the whole system have been then carried out. The normal contact stiffness has been simulated introducing in the model an equivalent layer on the top and on the bottom of the sample in contact with the disc. In a second step, the method has been also validated by taking in account the contact stiffness directly by the value of the normal contact stiffness parameter in the penalty modelling of the interfaces. The results of the modal analysis (frequency of the investigated mode) of the updated numerical model have been compared with the experiments (frequency response function) to fit as better as possible the value of the contact stiffness. A parametrical modal analysis has been performed as a function of the different lengths of the sample and as a function of different average contact pressures imposed experimentally. For the higher values of the average contact pressure, imposed experimentally, different dead masses are added respectively on the top of the guide bar to account for the dynamic effect of the mass in the numerical analysis as in the experiments.

\section{CONTACT STIFFNESS ESTIMATION IN STATIC CONDITION}

An extensive measurement campaign has been conducted for the estimation of the contact stiffness in static conditions for PMMA cylindrical samples with diameter $\mathrm{D}=12 \mathrm{~mm}$.

Three specimens for each length $(\mathrm{L}=10 \mathrm{~mm}, \mathrm{~L}=15 \mathrm{~mm}, \mathrm{~L}=20$ $\mathrm{mm})$ and for two values of the roughness parameter $(\mathrm{Ra}=1 \mu \mathrm{m}$ and $\mathrm{Ra}=6 \mu \mathrm{m}$ ) have been tested, according to the following protocol:

- the sample is put in contact between the disc and the guide bar;

- then the system is excited with an hammer impact on the upper surface of the bar and the impulsive system response along the normal direction respect to the contact is recorded by the accelerometer;

- The frequency response function (FRF) is calculated in order to identify the frequency of the investigated mode.
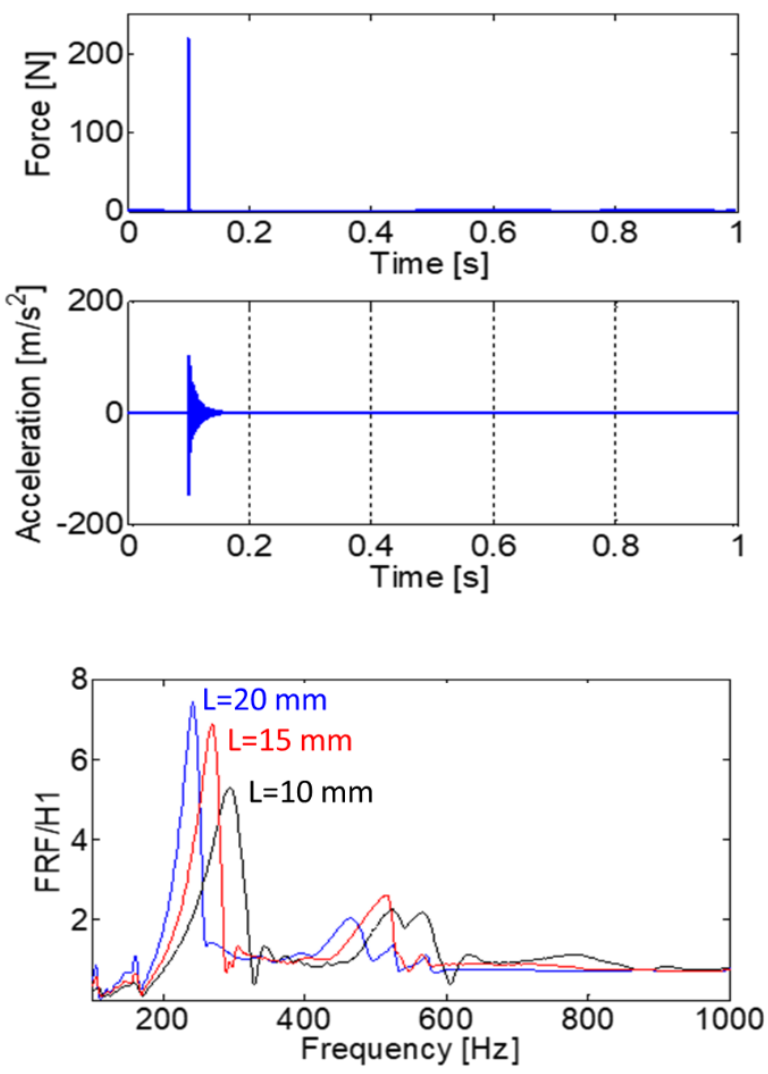

Figure 5. (Up) Acceleration and force signals over the time recorded due to the impact excitation for a single measurement; (down) frequency response function of the system for different lengths of the tested samples.

$17^{\text {th }}$ LACCEI International Multi-Conference for Engineering, Education, and Technology: "Industry, Innovation, And Infrastructure for Sustainable Cities and Communities”, 24-26 July 2019, Jamaica. 
The previous step has been repeated for each of the following average contact pressure values: $0.14 \mathrm{MPa}, 0.25 \mathrm{MPa}, 0.35$ $\mathrm{MPa}, 0.57 \mathrm{MPa}$ and $1 \mathrm{MPa}$. After performing the test with the highest pressure, a last measurement is performed with the lower value of the average contact pressure $(0.14 \mathrm{MPa})$ in order to verify the occurrence of residual plastic deformation at the interface that could modify the natural frequency of the investigated mode. The evolution of the natural frequency of the investigated mode as a function of the contact pressure and as a function of the sample length is reported in Figure 6. The decreasing behaviour of the mode frequency is influenced by the added masses, which are used to increase the average contact pressure.

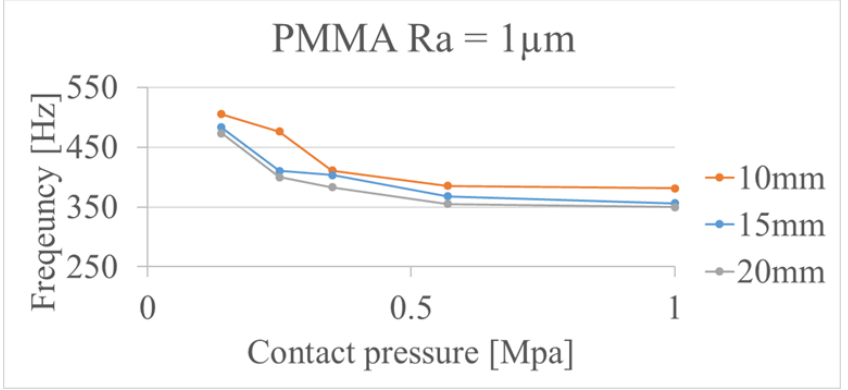

Figure 6. Frequency of the investigated mode as a function of the contact pressure and sample length for $\mathrm{Ra}=1 \mu \mathrm{m}$.

Figure 7 shows a comparison of the results between numerical and experimental tests in terms of the natural frequency of the investigated system mode. Figure 7 shows as the computed contact stiffness value allowed for obtaining a good quantitative agreement between experiments and numerical results in the case of an average contact pressure of $0.14 \mathrm{MPa}$ and for a surface roughness of $\mathrm{Ra}=1 \mu \mathrm{m}$.

With the same model and same boundary conditions used in the previous case, the default penalty contact stiffness value $(\mathrm{k}=6 \mathrm{e} 13 \mathrm{~Pa} / \mathrm{m})$ calculated by the software (ANSYS) has been introduced in the model. The comparison with the experiments highlights a crucial difference in term of natural frequency of the considered system mode, confirming the unrealistic values of the contact stiffness computed in the commercial codes, which lead to completely wrong results, overestimating the frequency of the system mode.

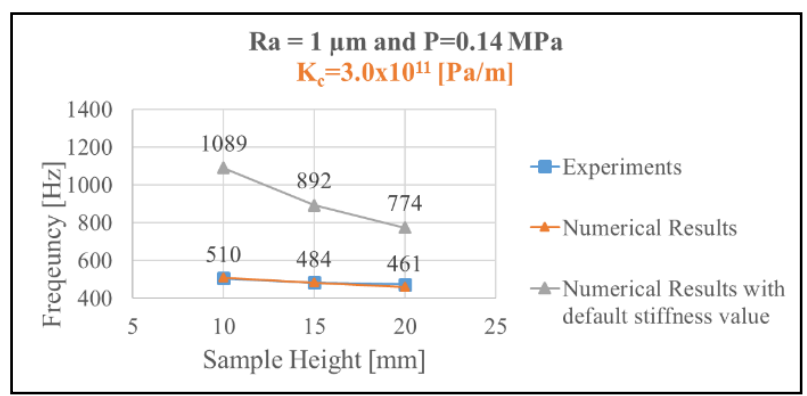

Figure 7. Experimental and numerical results for PMMA samples and for surface roughness of $\mathrm{Ra}=1 \mu \mathrm{m}$ and average contact pressure of $\mathrm{P}=0.14 \mathrm{MPa}$.
For the contact stiffness estimation, the numerical contact stiffness has been updated, for both $\mathrm{Ra}=1 \mu \mathrm{m}$ and $\mathrm{Ra}=6 \mu \mathrm{m}$ (Figure 8) and for each average contact pressure. Varying the contact stiffness parameter used in the penalty method to describe the contact interface, it has been possible to fit the value of the natural frequencies for each combination of specimens, average contact pressure and surface roughness parameter (Ra).

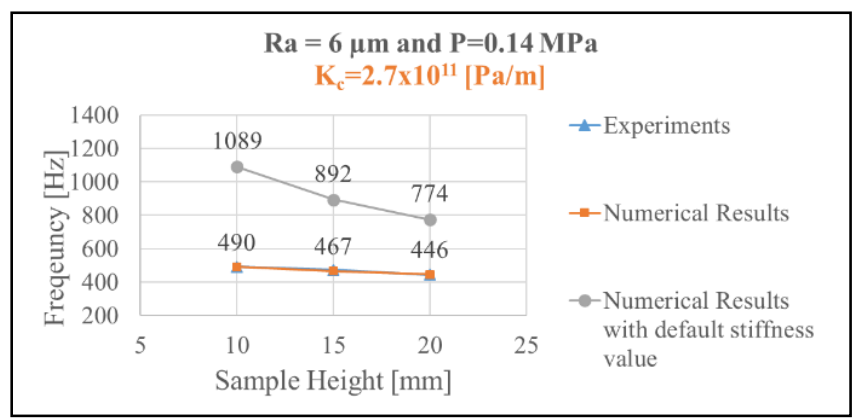

Figure 8. Experimental and numerical results for PMMA samples and for surface roughness of $\mathrm{Ra}=6 \mu \mathrm{m}$ and average contact pressure of $\mathrm{P}=0.14 \mathrm{MPa}$

Figure 9 shows the trend of the contact stiffness as a function of the average contact pressure for both surfaces of $\mathrm{Ra}=1 \mu \mathrm{m}$ and $\mathrm{Ra}=6 \mu \mathrm{m}$. The figure highlights how the contact stiffness value increases as a function of the average contact pressure for both roughness parameters, as found in the literature by analytical and simplified numerical models $[23,26]$. As expected, a difference in the contact stiffness value is remarkable (Figure 6) as a function of the different surface roughness. A lower surface roughness parameter leads to have a higher estimated value of the normal contact stiffness as expected.

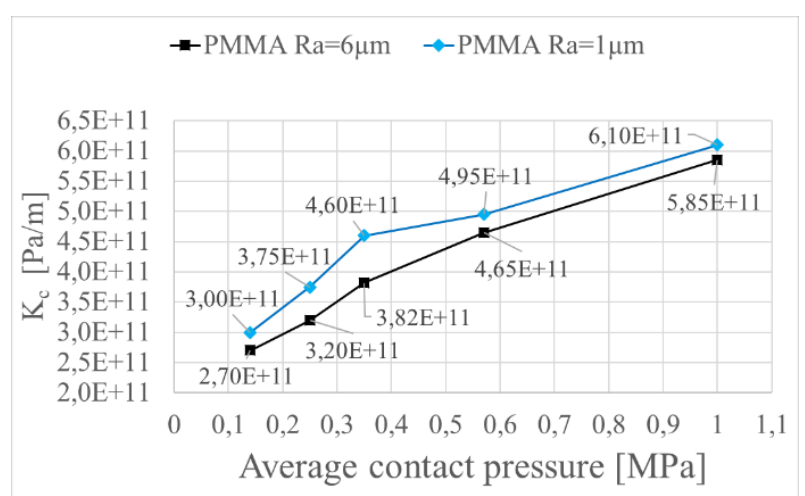

Figure 9. Normal contact stiffness as a function of the average contact pressure for surface roughness of $\mathrm{Ra}=1 \mu \mathrm{m}$ (blue points) and $\mathrm{R} a=6 \mu \mathrm{m}$ (black points).

\section{PRELIMINARY RESULTS FOR CONTACT STIFFNESS ESTIMATION IN SLIDING CONDITION}

In order to perform experimental tests in sliding condition, the disc is put in rotation, while the support is maintained fix. A

$17^{\text {th }}$ LACCEI International Multi-Conference for Engineering, Education, and Technology: "Industry, Innovation, And Infrastructure for Sustainable Cities and Communities", 24-26 July 2019, Jamaica. 
thin holding plate has been added to the end of the guide bar in order to avoid translation between the support and the tested sample.

To minimize the effect on the specimen on the dynamic response, the plate is only $0.5 \mathrm{~mm}$ tick and the radius of the through-hole is larger than the radius of the specimens, reducing the contact surface at the side of the sample. The test was conducted according to the procedure described below:

- The system has been excited in static condition (no rotation imposed on the disc), using the instrumented hammer, with a single impact on the guide bar and recording the acceleration of the system, establishing a reference measurement needed for comparing the subsequent tests (Figure 10);

- The drive motor has been activated, rotating the disc at a speed of 1.5 revolutions per second, and a sequence of impact excitations have been provided during the sliding test (Figure 10);

- After 500 seconds, the motor has been deactivated, arresting the motion of the disc and an impact excitation has been given to the system again.

Figure 10 shows a preliminary sliding test performed with PMMA sample with length $\mathrm{h}=10 \mathrm{~mm}$, an imposed average pressure of $0.35 \mathrm{MPa}$ for a surface roughness of $\mathrm{Ra}=1 \mu \mathrm{m}$. The first curve in the figure represents the signal of the excitation force given to the system during the entire test. The second curve represents the acceleration response of the system to the impulsive excitation performed during the test. The blue curve represents the FFT of the acceleration signal related to the first impulsive excitation (no rotation of the disc), where the system is fixed (static condition). On the other hand, the orange curve is related to the FFT of the acceleration signal due to the impulsive excitation during the sliding test (rotation of the disc) at around $90 \mathrm{~s}$, as shown in the Figure 10. The comparison of the two spectrum curves shows a slight increasing of the investigated mode frequency and therefore an increasing of the related contact stiffness, which can be associated to the evolution of the topography of the contact interface in term of roughness and third body layer.

The performed tests allowed for investigating the evolution of the contact stiffness during the entire sliding tests as shown in Figure 11. The behaviour of the contact stiffness, highlighted in the figure is characterized by a fluctuation of the contact stiffness that could be attributed to the evolution and modification of the contact interface. Figure 12 shows the topography of the contact surface at the end of the test. The surface is characterized by evident traces of the frictional sliding with accumulation of the third body at the edge of the sample.

Further tests are planned as the next steps of this work. The effects of the material, roughness, imposed rotational velocity and third body layer will be investigated for the sliding configuration.
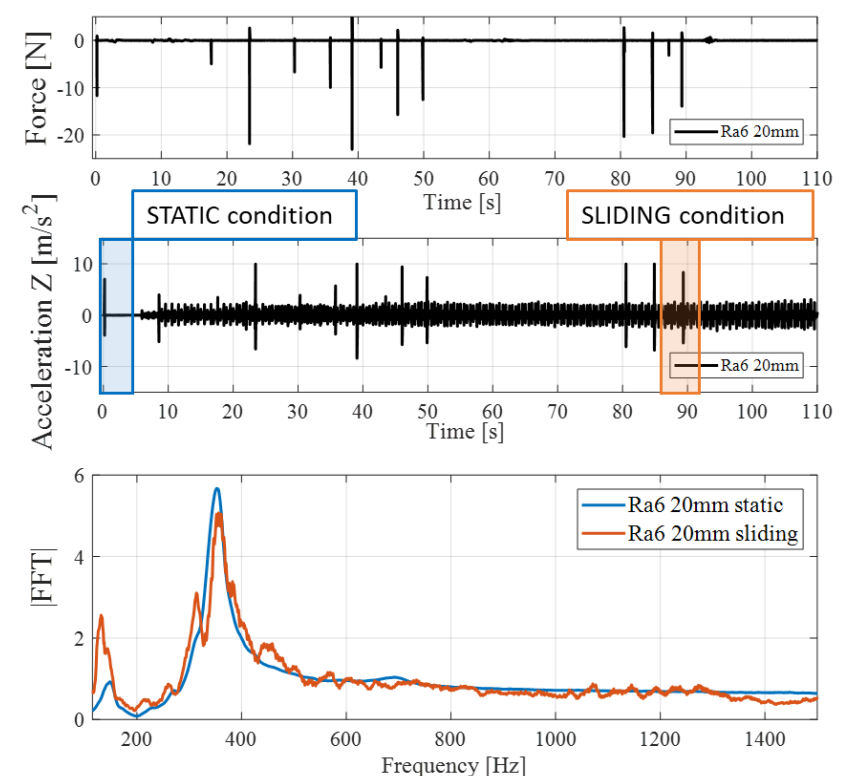

Figure 10. From top to bottom: signal force (hammer impact), acceleration response and spectrum of the acceleration for the static condition (1s) and sliding condition (90s).

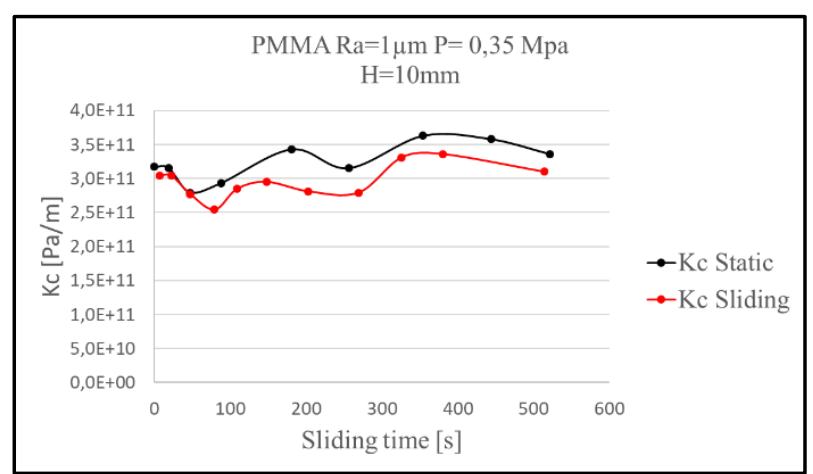

Figure 11. Evolution of the contact stiffness in static and sliding condition.

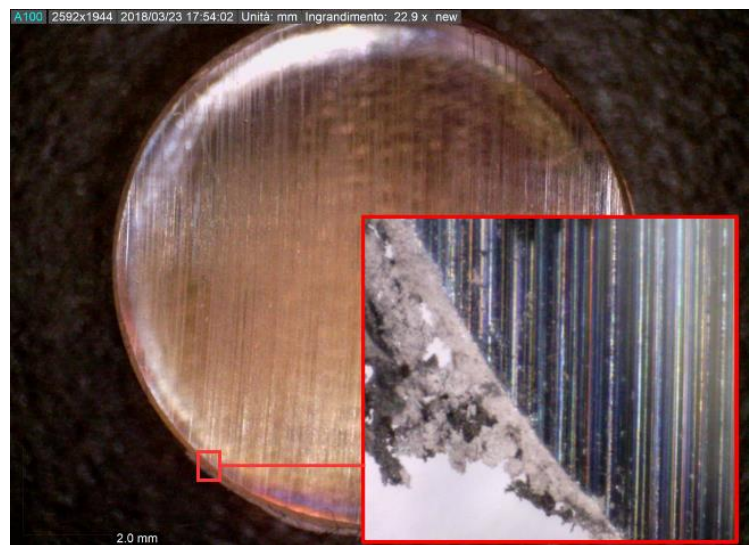

Figure 12. Surface topography related to the sliding surface in contact with the steel disc at the end of the sliding test.

$17^{\text {th }}$ LACCEI International Multi-Conference for Engineering, Education, and Technology: "Industry, Innovation, And Infrastructure for Sustainable Cities and Communities”, 24-26 July 2019, Jamaica. 


\section{CONCLUSIONS}

The quantitative estimation of contact stiffness between two bodies in contact represents a significant improvement in the numerical modelling of dynamic frictional systems. To achieve such a result, an experimental and numerical procedure has been developed, allowing to investigate the contact stiffness evolution with the main contact parameters, obtaining consistent and reproducible results.

In frictional contact systems, the real contact stiffness is a function of several operational parameters (roughness, contact pressure, third body rheology) and affects both the global dynamic response of the system and the local contact behaviour (stress and strain at the contact interface). The developed approach allows for estimating the contact stiffness in sticking and sliding conditions under well controlled parameters, useful to be introduced into finite element modes for both static and dynamic contact simulations, such as, for example, CEA and nonlinear transient analysis for brake squeal prediction.

\section{REFERENCES}

[1] F. Coppo, G. Pepe, N. Roveri, and A. Carcaterra, "A multisensing setup for the intelligent tire monitoring," Sensors (Switzerland), Article vol. 17, no. 3, 2017, Art no. 576, doi: 10.3390/s17030576.

[2] N. Roveri, G. Pepe, and A. Carcaterra, "On line estimation of rolling resistance for intelligent tires," in Proceedings of ISMA 2016 - International Conference on Noise and Vibration Engineering and USD2016 - International Conference on Uncertainty in Structural Dynamics, 2016, pp. 1725-1740.

[3] I. Ghezzi et al., "Damage evolution and contact surfaces analysis of high-loaded oscillating hybrid bearings," Wear, vol. 406-407, pp. 112, 2018/07/15/ 2018, doi: https://doi.org/10.1016/j.wear.2018.03.016.

[4] D. Tonazzi et al., "Numerical analysis of contact stress and strain distributions for greased and ungreased high loaded oscillating bearings," Wear, vol. 376-377, pp. 1164-1175, 2017/04/15/ 2017, doi: https://doi.org/10.1016/j.wear.2016.11.037.

[5] A. Lazzari, D. Tonazzi, G. Conidi, C. Malmassari, A. Cerutti, and F. Massi, "Experimental evaluation of brake pad material propensity to stick-slip and groan noise emission," Lubricants, Article vol. 6, no. 4, 2018, Art no. 107, doi: 10.3390/lubricants6040107.

[6] A. Lazzari, D. Tonazzi, and F. Massi, "Squeal propensity characterization of brake lining materials through friction noise measurements," Mechanical Systems and Signal Processing, vol. 128, pp. 216-228, 2019/08/01/ 2019, doi: https://doi.org/10.1016/j.ymssp.2019.03.034.

[7] D. Tonazzi, F. Massi, L. Baillet, J. Brunetti, and Y. Berthier, "Interaction between contact behaviour and vibrational response for dry contact system," Mechanical Systems and Signal Processing, vol. 110, pp. 110-121, 2018/09/15/ 2018, doi: https://doi.org/10.1016/j.ymssp.2018.03.020.

[8] D. Tonazzi, F. Massi, A. Culla, L. Baillet, A. Fregolent, and Y. Berthier, "Instability scenarios between elastic media under frictional contact," Mechanical Systems and Signal Processing, vol. 40, no. 2, pp. 754-766, 11// 2013, doi: http://dx.doi.org/10.1016/j.ymssp.2013.05.022.

[9] D. Tonazzi et al., "Experimental and numerical characterization of system response under dry frictional contact," in ISMAInternational Conference on Noise and Vibration Engineering, ed. Leuven, 2014.

[10] D. Tonazzi, F. Massi, L. Baillet, A. Culla, M. Di Bartolomeo, and Y. Berthier, "Experimental and numerical analysis of frictional contact scenarios: from macro stick-slip to continuous sliding,"
Meccanica, vol. 50, no. 3, pp. 649-664, 2015/03/01 2015, doi: 10.1007/s11012-014-0010-2.

[11] M. Di Bartolomeo, F. Morelli, D. Tonazzi, F. Massi, and Y. Berthier, "On the role of friction induced vibrations in tactile perception," in Proceedings of ISMA 2016 - International Conference on Noise and Vibration Engineering and USD2016 International Conference on Uncertainty in Structural Dynamics, 2016, pp. 3099-3110.

[12] Y. Berthier and D. Play, "Wear mechanisms in oscillating bearings," Wear, vol. 75, no. 2, pp. 369-387, 1982/01/15 1982, doi: http://dx.doi.org/10.1016/0043-1648(82)90159-4.

[13] I. El-Thalji and E. Jantunen, "A descriptive model of wear evolution in rolling bearings," Engineering Failure Analysis, vol. 45, pp. 204224, 10// 2014, doi: http://dx.doi.org/10.1016/j.engfailanal.2014.06.004.

[14] E. H. Komba, F. Massi, N. Bouscharain, G. Le Jeune, Y. Berthier, and Y. Maheo, "Experimental damage analysis in high loaded oscillating bearings," Tribology International, vol. 102, pp. 507515, 10// 2016, doi: http://dx.doi.org/10.1016/j.triboint.2016.06.008.

[15] F. Massi, J. Rocchi, A. Culla, and Y. Berthier, "Coupling system dynamics and contact behaviour: Modelling bearings subjected to environmental induced vibrations and 'false brinelling' degradation," Mechanical Systems and Signal Processing, vol. 24, no. 4, pp. 1068-1080, 5// 2010, doi: http://dx.doi.org/10.1016/j.ymssp.2009.09.004

[16] B. Hervé, J. J. Sinou, H. Mahé, and L. Jézéquel, "Analysis of squeal noise and mode coupling instabilities including damping and gyroscopic effects," European Journal of Mechanics - A/Solids, vol. 27 , no. 2, pp. 141-160, 3// 2008, doi: http://dx.doi.org/10.1016/j.euromechsol.2007.05.004.

[17] N. Hoffmann and L. Gaul, "Effects of damping on mode-coupling instability in friction induced oscillations," ZAMM - Journal of Applied Mathematics and Mechanics / Zeitschrift für Angewandte Mathematik und Mechanik, vol. 83, no. 8, pp. 524-534, 2003, doi: 10.1002/zamm.200310022.

[18] D. Tonazzi, F. Massi, A. Culla, A. Fregolent, and Y. Berthier, "Role of damping on contact instability scenarios," in 5th World Tribology Congress, WTC 2013, 2013, vol. 1, pp. 755-758.

[19] S. M. Lee, M. W. Shin, W. K. Lee, and H. Jang, "The correlation between contact stiffness and stick-slip of brake friction materials," Wear, Article vol. 302, no. 1-2, pp. 1414-1420, 2013, doi: 10.1016/j.wear.2012.12.017.

[20] S. Lee and H. Jang, "Effect of plateau distribution on friction instability of brake friction materials," Wear, vol. 400-401, pp. 1-9, 2018/04/15/ 2018, doi: https://doi.org/10.1016/j.wear.2017.12.015.

[21] V. Magnier, J. F. Brunel, and P. Dufrénoy, "Impact of contact stiffness heterogeneities on friction-induced vibration," International Journal of Solids and Structures, vol. 51, no. 9, pp. 1662-1669, 5/1/ 2014, doi: http://dx.doi.org/10.1016/j.ijsolstr.2014.01.005.

[22] R. Pohrt and V. L. Popov, "Contact stiffness of randomly rough surfaces," Scientific Reports, Article vol. 3, p. 3293, 11/21/online 2013, doi: 10.1038/srep03293.

[23] "Contact of nominally flat surfaces," Proceedings of the Royal Society of London. Series A. Mathematical and Physical Sciences, 10.1098/rspa.1966.0242 vol. 295, no. 1442, p. 300, 1966.

[24] R. S. Dwyer-Joyce, B. W. Drinkwater, and A. M. Quinn, "The Use of Ultrasound in the Investigation of Rough Surface Interfaces," Journal of Tribology, vol. 123, no. 1, pp. 8-16, 2000, doi: 10.1115/1.1330740.

[25] S. A. Syed Asif, K. J. Wahl, R. J. Colton, and O. L. Warren, "Quantitative imaging of nanoscale mechanical properties using hybrid nanoindentation and force modulation," Journal of Applied Physics, vol. 90, no. 3, pp. 1192-1200, 2001/08/01 2001, doi: 10.1063/1.1380218.

[26] D. P. Hess and N. J. Wagh, "Evaluating Surface Roughness From Contact Vibrations," Journal of Tribology, vol. 117, no. 1, pp. 6064, 1995, doi: 10.1115/1.2830607.

$17^{\text {th }}$ LACCEI International Multi-Conference for Engineering, Education, and Technology: "Industry, Innovation, And Infrastructure for Sustainable Cities and Communities", 24-26 July 2019, Jamaica. 
[27] M. Gonzalez-Valadez, A. Baltazar, and R. S. Dwyer-Joyce, "Study of interfacial stiffness ratio of a rough surface in contact using a spring model," Wear, vol. 268, no. 3, pp. 373-379, 2010/02/04/ 2010, doi: https://doi.org/10.1016/j.wear.2009.08.022.

[28] A. A. Polycarpou and A. Soom, "Boundary and Mixed Friction in the Presence of Dynamic Normal Loads: Part I-System Model," Journal of Tribology, vol. 117, no. 2, pp. 255-260, 1995, doi: 10.1115/1.2831239.

[29] A. I. Vakis et al., "Modeling and simulation in tribology across scales: An overview," Tribology International, Review vol. 125, pp. 169-199, 2018, doi: 10.1016/j.triboint.2018.02.005.

[30] A. Papangelo, N. Hoffmann, and M. Ciavarella, "Load-separation curves for the contact of self-affine rough surfaces," Scientific Reports, Article vol. 7, no. 1, 2017, Art no. 6900, doi: 10.1038/s41598-017-07234-4.

$17^{\text {th }}$ LACCEI International Multi-Conference for Engineering, Education, and Technology: "Industry, Innovation, And Infrastructure for Sustainable Cities and Communities", 24-26 July 2019, Jamaica. 